\title{
Evironmental pollutant perfluorodecanoic acid upregulates cIAP2 to suppress gastric cell senescence
}

\author{
ZHUN ZHANG ${ }^{1,2^{*}}$, NING SONG ${ }^{1 *}$, YANPING PENG ${ }^{1}$, ZIYAN FAN $^{3}$, MINGYONG HAN $^{4}$, \\ MIN ZHAO $^{5}$, TIANYI DONG ${ }^{1,2}$ and SHILI LIU ${ }^{1}$
}

\begin{abstract}
${ }^{1}$ Department of Medical Microbiology, School of Basic Medical Sciences, Shandong University, Jinan, Shandong 250012; ${ }^{2}$ Department of Breast Thyroid Surgery, Shandong Provincial Hospital, Shandong University, Jinan, Shandong 250021; ${ }^{3}$ China National Tobacco Quality Supervision and Test Center, Zhengzhou, Henan 450001; ${ }^{4}$ Cancer Therapy and Research Center, Shandong Provincial Hospital, Shandong University, Jinan, Shandong 250021; ${ }^{5}$ Department of Clinical Laboratory, Qilu Hospital of Shandong University, Qingdao, Shandong 266035, P.R. China
\end{abstract}

Received January 31, 2018; Accepted October 22, 2018

DOI: 10.3892/or.2018.6856

\begin{abstract}
The role of perfluorodecanoic acid (PFDA) in gastric carcinogenesis and its mechanism remains unknown. Our previous research revealed that PFDA regulated the growth of human gastric cells. However, its core molecules and basic mechanisms are still not clear. In the present study, cDNA microarrays were used to determine mRNA changes in AGS cells after treatment with PFDA. DAVID analysis of the genes with $>2$-fold increased expression in microarray data revealed five genes which were involved in cancer pathways. The most upregulated gene was cIAP2, whose upregulation in AGS was confirmed by western blot analysis and quantitative PCR (qPCR) analyses. In order to investigate the role of cIAP2 in cell proliferation, cIAP2 siRNA was employed to regulate cIAP2 expression following PFDA treatment. The results revealed that the growth rate of cIAP2-knockdown cells was reduced by about $50 \%$ compared to the control. Given that our previous flow cytometric assays revealed no significant change (3.7 vs. $6.4 \%$ ) in the percentage of apoptotic cells when PFDA was added to the medium and cIAP2 expression was upregulated, we next applied flow cytometry to assess whether cIAP2 would lead to cell cycle variations. The research data revealed that the proportion of cells in the G1, S and G2 phases was not significantly altered with the decrease of cIAP2 expression. Finally, the role of cIAP2 in AGS cell senescence was investigated, and the results indicated that cell senescence was significantly increased in the cIAP2 siRNA group in
\end{abstract}

Correspondence to: Professor Shili Liu, Department of Medical Microbiology, School of Basic Medical Sciences, Shandong University, 44 Wenhuaxi Road, Jinan, Shandong 250012, P.R. China

E-mail: liushili@sdu.edu.cn

*Contributed equally

Key words: perfluorodecanoic acid, cIAP2, cell senescence, gastric cancer comparison to the control siRNA group. Since p53 has been identified as a tumor suppressor and its molecular alterations are common in different human tumors, we investigated the relationship of p53 with cIAP2. The experimental results demonstrated that cIAP2 regulated the expression of p53 and thus was likely to be a potential mechanism for PFDA-induced growth promotion. Overall, the results revealed that PFDA may suppress cellular senescence induced by p53 through the regulation of cIAP2 protein expression.

\section{Introduction}

Gastric cancer is a common malignancy, accounting for $\sim 10 \%$ of all invasive cancers in the world; it is the third leading cause of cancer-related deaths. In China, the number of gastric cancer cases and deaths has increased along with population changes and continuous increase of environmental pollution. The positive correlation between gastric cancer and environmental pollution has been confirmed (1-3), but the underlying mechanism remains unclear.

As a class of synthetic chemicals with surface-active properties, perfluorinated compounds (PFCs) are widely used as surfactants and surface protectants in many applications due to their chemical non-reactivity, thermal stability and non-conductivity, including lubricants, paints, polishes, fire-fighting foams and food packaging $(4,5)$. Perfluorinated compounds are globally detectable in the environment $(6,7)$, wildlife (8-10) and humans (8-13). In recent years, with the emergence of toxicity data from laboratory animals $(14,15)$, perfluorocompounds have been recognized as public health issues due to their persistence in the environment $(16,17)$. Perfluorodecanoic acid (PFDA), a perfluorinated carboxylic acid, is known to induce a variety of peroxisomal enzymes as well as a series of mitochondria, microsomes and cytosolic enzymes and proteins involved in lipid metabolism (18-21). In vivo, PFDA is a highly potent and persistent peroxisome proliferator with several times the toxicity of perfluorooctanoic acid (PFOA) $(22,23)$. PFDA has been reported to cause hypophagia, severe weight loss, bradycardia, hypothermia and decreased serum thyroid hormone levels in rats $(23,24)$. The 
cellular and physiological effects reported for PFDA include reproductive $(25,26)$, endocrine $(27,28)$, hepatotoxic and lipid metabolism $(29,30)$ and immune system disorders (31). PFDA concentrations in human blood and organs are much higher than PFOA, and its serum elimination half-life may persist for several years. However, despite the evidence of PFDA toxicity little is known about its mechanism of action in tumor promotion such as gastric cancer.

PFDA is found in air, food and water, and particularly $0.139 \mathrm{ng} / \mathrm{ml}$ of PFDA was found in snowfall in the surrounding areas of Beijing, China (7). In China, the main source of PFDA is through the contaminated drinking water and food, especially seafood (32). It is crucial to reveal the signaling pathways and molecules involved in PFDA-induced toxic effects. In a previous study, we found that PFDA induced gastric cancer cell proliferation by inhibiting senescence (33), however, the important regulatory molecules in this process had not yet been established. In the present study, we revealed the pivotal role of cIAP2 in mediating PFDA-induced senescence inhibition.

\section{Materials and methods}

Cell culture and transfections. Gastric adenocarcinoma cell line AGS and MGC-803 cells were supplied by the Cell Bank of Shanghai Institute of Cell Biology, Chinese Academy of Sciences (Shanghai, China) were maintained in our laboratory. AGS cells were cultured in Ham's F-12 medium (HyClone; GE Healthcare Life sciences, Logan, Utah, USA) containing $10 \%$ FCS and $1 \%$ penicillin-streptomycin. FuGENEs HD Transfection Reagent (Roche Applied Science, Penzberg, Switzerland) was used for transfection. The cIAP2 siRNA transfection procedure was performed according to the manufacturer's instructions (Roche Applied Science, Penzberg, Switzerland), and subsequent qPCR or western blot assays were performed $24 \mathrm{~h}$ after transfection.

RNA extraction and quantitative real-time PCR. Total cellular RNA was extracted with TRIzol (Life Technologies; Thermo Fisher Scientific, Inc., Waltham, MA, USA) according to the protocol provided by the manufacturer. First-strand cDNA was synthesized from $1 \mu \mathrm{g}$ total cellular or tissue RNA using the RevertAid $^{\mathrm{TM}}$ First Strand cDNA Synthesis Kit (Thermo Fisher Scientific, Inc.) with random primers. Then cDNA was amplified for quantitative real-time PCR, and the specific primers used were as follows: cIAP2 forward, 5'-GCCTGATGCTGG ATAACT-3' and reverse, 5'-GAATAAGAGCCACGGAAA-3'; $\beta$-actin forward, 5'-AGTTGCGTTACACCCTTTCTTG-3' and reverse, 5'-CACCTTCACCGTTCCAGTTTT-3'; FGF18 forward, 5'-TGGTACGTGGGCTTCACC-3' and reverse, 5'-ATCCGACGGGACCTCTTG-3'; FOS forward, 5'-GTC TCCAGTGCCAACTTCAT-3' and reverse, 5'-CAGCCATCT TATTCCTTTCC-3'; p53 forward, 5'-GCGAGCACTGCC CAACAACA-3' and reverse, 5'-GGATCTGAAGGGTGA AATATTCT-3'. The real-time PCR reactions were performed at: $95^{\circ} \mathrm{C}, 10 \mathrm{sec}$ (denaturation); $55^{\circ} \mathrm{C}, 30 \mathrm{sec}$ (annealing); $72^{\circ} \mathrm{C}$, $30 \mathrm{sec}$ (extension) for 35 cycles. The real-time PCR reactions were performed on an ABI7000 Fast Real-Time PCR System with SYBR Premix Ex Taq ${ }^{\mathrm{TM}}$ (Takara Bio, Inc., Shiga, Japan) according to the manufacturer's procedures.
Western blot analysis. Protein concentation was determined by BCA Protein Assay kit (cat. no. P0006; Beyotime Institute of Biotechnology, Shanghai, China). Western blot analysis was performed as previously described (33). Briefly, cell lysates (20 $\mu \mathrm{g} /$ lane) were separated on $10 \%$ SDS polyacrylamide gel and then were transferred to a poly(vinylidene fluoride) membrane. The membrane was then blocked by $5 \%$ skimmed milk for $1 \mathrm{~h}$ at room temperature. cIAP2 protein was detected by a 1:2,000 diluted rabbit polyclonal IgG (cat. no. TA590350; OriGene Co., Ltd., Beijing, China) for overnight, then treated with goat 1:5,000 diluted secondary antibody (cat. no. 172-1013; Bio-Rad Laboratories, Inc., Irvine, CA, USA) for $1 \mathrm{~h}$, and visualized using an enhanced chemiluminescence system (Amersham; GE Healthcare, Chicago, IL, USA). $\beta$-actin was used as reference protein (antibody was purchased from Beyotime Institute of Biotechnology, Shanghai, China; cat. no. AA128, 1:2,000 dilution was used). The density of the bands was quantitated using the NIH ImageJ software package (bundled with 64-bit Java 1.8.0_112; National Institutes of Health, Bethesda, MD, USA). The intensity of cIAP2 expression was judged by the ratio of their expression in the experimental groups to their corresponding expression in the control groups, and a ratio of $>1.0$ was considered to be an indication of overexpression.

Colony formation assay. Gastric cell line AGS cultured in a 6-well plate $\left(2 \times 10^{5}\right.$ cells/well) was treated with PFDA and transfected with cIAP2 siRNA using FuGENEs HD Transfection reagent (Roche Applied Science). After $72 \mathrm{~h}$ of growth the cells were digested with trypsin and counted, and 300 cells were transferred to a new well of a 6-well plate and medium containing $10 \%$ FBS serum was added to make up a volume of $3 \mathrm{ml}$. Following a week of cell growth at $37^{\circ} \mathrm{C}$, the formation of cell clones could be visually observed. After washing 3 times with PBS buffer, the cells were fixed for 10 min with $1 \mathrm{ml}$ of methanol in each well at room temperature. Then $1 \mathrm{ml}$ diluted Giemsa dye was added to each well and incubated at room temperature for $\sim 20-25 \mathrm{~min}$. Finally, the wells were washed with PBS until no residual background Giemsa dye was observed and the 6-well plate was scanned for colony counting and analysis.

Cell cycle analysis. AGS cells $\left(5 \times 10^{5}\right)$ in a well of a 6 -well plate were treated with PFDA and transfected with cIAP2 siRNA, incubated for varied time-points before the cells were digested and harvested by centrifugation at $1,400 \mathrm{x}$ g. Then, the cells were fixed gently (drop by drop) in $75 \%$ ethanol overnight at $-20^{\circ} \mathrm{C}$ and then re-suspended in PBS containing $50 \mathrm{mg} / \mathrm{l} \mathrm{PI}, 1 \mathrm{~g} / \mathrm{l} \mathrm{RNase}$ and $0.1 \%$ Triton X-100. After $30 \mathrm{~min}$ at $37^{\circ} \mathrm{C}$ in the dark, the cells were analyzed with flow cytometry equipped with an argon laser at $488 \mathrm{~nm}$. Then the cell cycle was determined and analyzed (34).

Microarry analysis. The microarray chip consisted of 27,326 different human cDNAs (Agilent Technologies, Inc., Wilmington, DE, USA), in which house-keeping gene glyceraldehyde-3-phosphate dehydrogenase (GAPDH) served as an internal control. The cDNAs from PFDA-treated AGS cells were labeled with $\mathrm{Cy} 3$, and the cDNAs from the control DMSO-treated AGS cells were labeled with Cy5. The labeled cDNAs were hybridized with a microarray chip under standard 
A

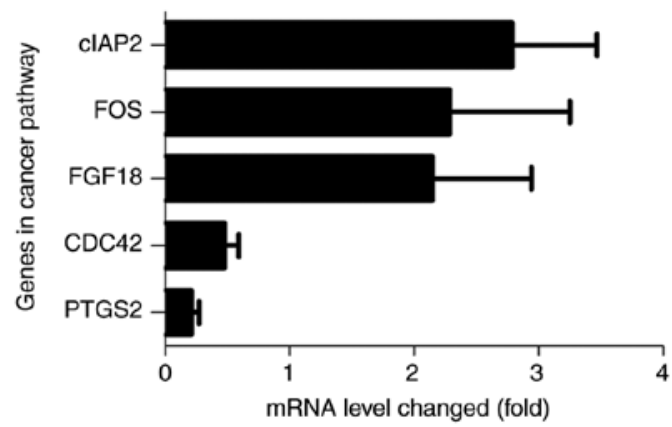

D



B
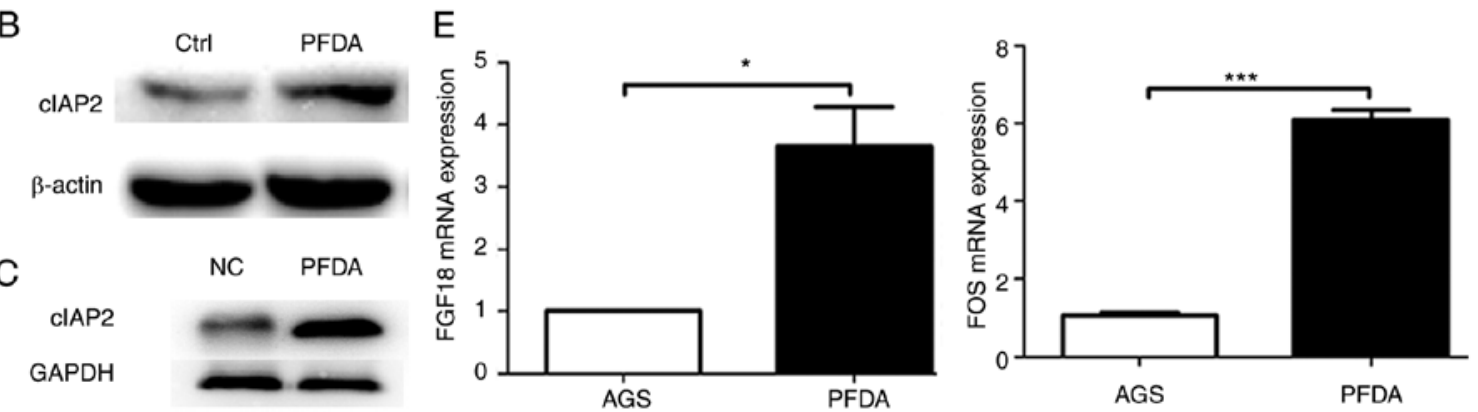

Figure 1. AGS treated with PFDA upregulates cIAP2 expression. (A) The expression of the five genes that were classified into cancer pathways by DAVID analysis from the microarray data, of which, three genes (cIAP2, FOS and FGF18) were upregulated. The expression of the most upregulated gene cIAP2 (BIRC3) was confirmed by (B) western blot and (D) quantitative PCR (qPCR) analysis. (C) MGC-803 cells treated with PFDA upregulated cIAP2 expression. (D) cIAP2 mRNA was increased in a dose-dependent manner in response to PFDA treatment in AGS cells. (E) Expression enhancement in FOS and FGF18 was ascertained by qPCR. Microarray analysis, western blotting and RT-qPCR were performed as described in the Materials and methods. Cells used for microarray and qPCR analysis were cells that were treated with PFDA for $60 \mathrm{~h}$; western blots harvested the proteins from the cells that were processed by PFDA for $72 \mathrm{~h}$. The PFDA concentration used to treat cells was $50 \mathrm{nM}$. ${ }^{*} \mathrm{P}<0.05 ;{ }^{* *} \mathrm{p}<0.01 ;{ }^{* * *} \mathrm{p}<0.001$. PFDA, perfluorodecanoic acid; DAVID, Database for Annotation, Visualization and Integrated Discovery.

conditions according to the manufacturer's instructions. The data was analyzed by DAVID v6.8 (https://david.ncifcrf.gov/) (the Database for Annotation, Visualization and Integrated Discovery).

siRNA interference. Chemically modified Stealth siRNA targeting cIAP2 and control siRNA were obtained from RiboBio Co., Ltd. (Guangzhou, China). The sequence for cIAP2 siRNA was 5'-CCTGTAAACTCCAGAGCAA-3'. Cells were transfected with siRNA using Lipofectamine 2000 (Life Technologies; Thermo Fisher Scientific, Inc.).

Senescence-associated $\beta$-galactosidase (SA- $\beta$-gal) activity assessment. SA- $\beta$-gal activity was detected using a staining kit of SA- $\beta$-gal $(35,36)$, and it was performed according to the manufacturer's protocol. Briefly, AGS cells were seeded into a 24-well plate. The cells were treated with PFDA on day 3. After treatment, the cells were washed with PBS (pH 7.2) twice before they were fixed with $3.7 \%$ formaldehyde in PBS for 3-5 min. Then, the SA- $\beta$-gal staining solution $(1 \mathrm{mg} / \mathrm{ml} \mathrm{X-gal,}$ $40 \mathrm{mM}$ citric acid/sodium phosphate $\mathrm{pH} 6.0,5 \mathrm{mM}$ potassium ferrocyanide, $150 \mathrm{mM} \mathrm{NaCl}$ and $2 \mathrm{mM} \mathrm{MgCl}_{2}$ ) was added into each well before the plate was incubated at $37^{\circ} \mathrm{C}$ for $12-16 \mathrm{~h}$ in the absence of $\mathrm{CO}_{2}$. Finally, the cells were rinsed with PBS and the plate was observed under a light microscope, in which the number of the SA- $\beta$-gal positive cells was recorded. The experiment was performed in triplicate.

Statistical analysis. Data were expressed as the mean \pm standard deviation (SD). Differences between two groups were compared using Student's t-tests. All experiments were repeated at least three times and $\mathrm{p}<0.05$ was considered to indicate a statistically significant difference.

\section{Results}

PFDA induces gastric cell proliferation and cIAP2 expression. Our previous research demonstrated that PFDA regulated the growth of human gastric cells. To determine the molecular factors involved in PFDA-induced growth acceleration of human gastric cells, cDNA microarray analysis was used to analyze gene changes in AGS cell mRNA levels following PFDA treatment. DAVID analysis of the genes that had $>2$-fold increased expression in microarray data revealed five genes which were involved in cancer pathways. In this pathway, three genes (cIAP2, FOS and FGF18) were upregulated (Fig. 1A). The expression of the most upregulated gene cIAP2 (BIRC3) was confirmed by western blot and quantitative PCR (qPCR) analyses (Fig. 1B and D). This expression enhancement of cIAP2 was also verified on the protein level of another gastric cell line, MGC-803 (Fig. 1C). Similarly, the expression enhancements in FOS and FGF18 were ascertained by qPCR (Fig. 1E). In addition, cIAP2 mRNA increased in a dose-dependent manner in response to PFDA treatment in AGS cells (Fig. 1D).

Knockdown of cIAP2 reduces AGS cell proliferation. In order to investigate the role of cIAP2 in cell proliferation, cIAP2 siRNA was used to regulate the expression of cIAP2 concomitant with PFDA treatment. Two siRNAs were used to knock down the expression of cIAP2 and the results 
A

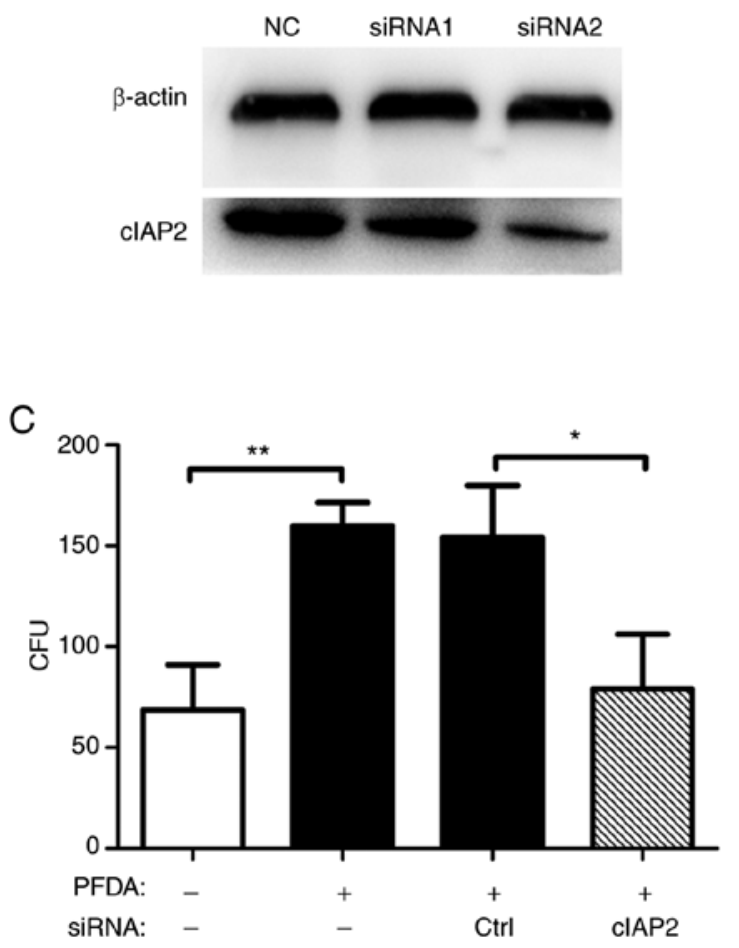

B

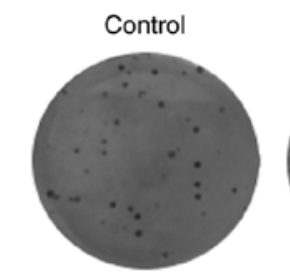

PFDA+Ctrl cIAP2 siRNA

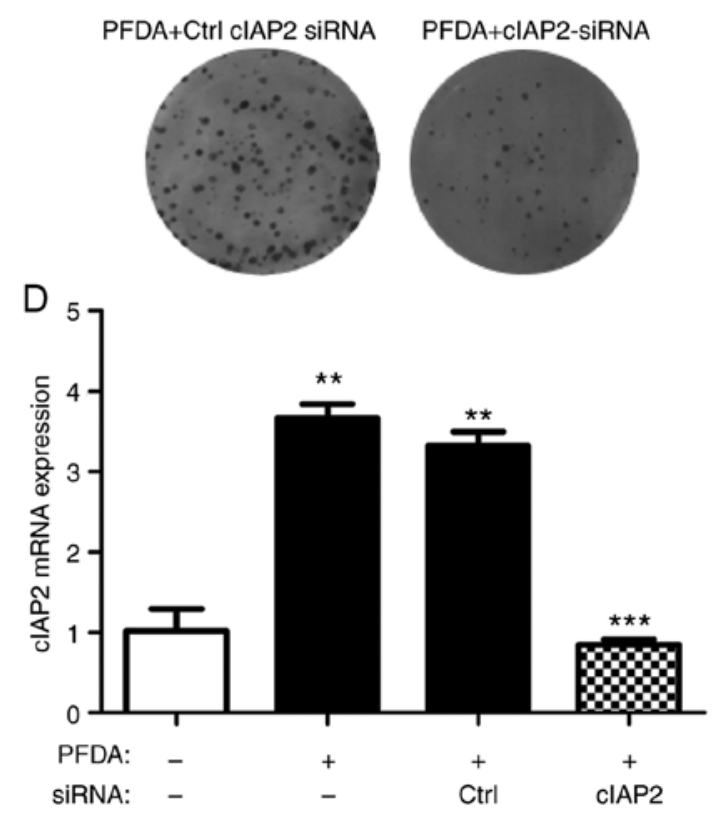

D

Figure 2. cIAP2 is involved in cell proliferation regulation. (A) Validation of cIAP2 siRNA. (B) cIAP2-siRNA transfected cells demonstrated significantly decreased colony-forming capability compared to control cells treated with PFDA only. (C) Quantification of colony-forming capability results. (D) cIAP2 mRNA levels in AGS cells with different treatments. Colony formation assays were performed as described in Materials and methods. Generally, 300 cells were used for the colony formation assay and $100 \mathrm{nM}$ siRNA was used for transfection. ${ }^{*} \mathrm{P}<0.05 ;{ }^{* *} \mathrm{p}<0.01 ;{ }^{* * *} \mathrm{p}<0.001$. PFDA, perfluorodecanoic acid.

demonstrated that siRNA2 was more efficient (Fig. 2A). Therefore, this siRNA was used to regulate cIAP2 expression in experiments. The effect on cell growth was examined. As revealed in Fig. $2 \mathrm{~B}$ and $\mathrm{C}$, the growth rate of transfected cells was reduced by about $50 \%$ compared to the control cells treated with PFDA only. This was consistent with the transcriptional pattern of cIAP2 mRNA in AGS cells (Fig. 2D), in which the expression was reduced after transfection.

cIAP2 has no effect on the cell cycle of AGS. Since previous flow cytometric assays revealed that there was no significant change in the percentage of apoptotic cells (3.7 vs. 6.4\%) in response to PFDA in the medium that upregulated cIAP2 expression, we next knocked down cIAP2 in AGS cells and applied flow cytometry to assess whether the cell cycle was influenced. As revealed in Fig. 3A and B, the results demonstrated that the percentage of G1, S and G2 phase cells was not significantly altered with the decrease of cIAP2 expression. These results indicated that cIAP2 has no effect on the the cell cycle of gastric epithelial cells in the presence of PFDA.

cIAP2 significantly inhibits AGS cell senescence. We then investigated the effect of cIAP2 expression on cellular senescence with siRNA knockdown of cIAP2 in AGS cells. As revealed in Fig. 4, cellular senescence of the cIAP2-siRNA group increased significantly when compared to the control
siRNA-treated group, which was confirmed by an increase in both the number of SA- $\beta$-gal-stained cells and staining intensity. Changes in cellular senescence induced by cIAP2 siRNA were also observed in MGC-803 cells (the bottom row of Fig. 4).

Knockdown of cIAP2 affects p53 expression. It has now been well established that dysfunction of p53 tumor suppressor is the most common molecular alteration in different human tumors and can result in inhibition of cell senescence and promotion of cell growth. To determine whether p53 expression was affected by cIAP2 in AGS cells, qRT-PCR and western blotting assays were conducted to analyze p53 mRNA and protein levels concomitant with cIAP2 interference. As revealed in Fig. 5A and B, the levels of p53 were significantly increased following cIAP2 siRNA transfection. These results indicated that cIAP2 regulated the expression of p53 and is therefore a possible mechanism for the growth promotion induced by PFDA. In addition, we also found that downstream p16 expression was affected by PFDA and cIAP2 (Fig. 5C), and the association between p16 expression and PFDA was ascertained in the MGC-803 cell line, where it was found that p16 responded to changes in PFDA concentrations (Fig. 5D). However, this response was not observed in the expression level of p21 (data not shown). Overall, the results indicated that PFDA suppressed cellular senescence induced by p53 through the regulation of cIAP2 protein expression. 

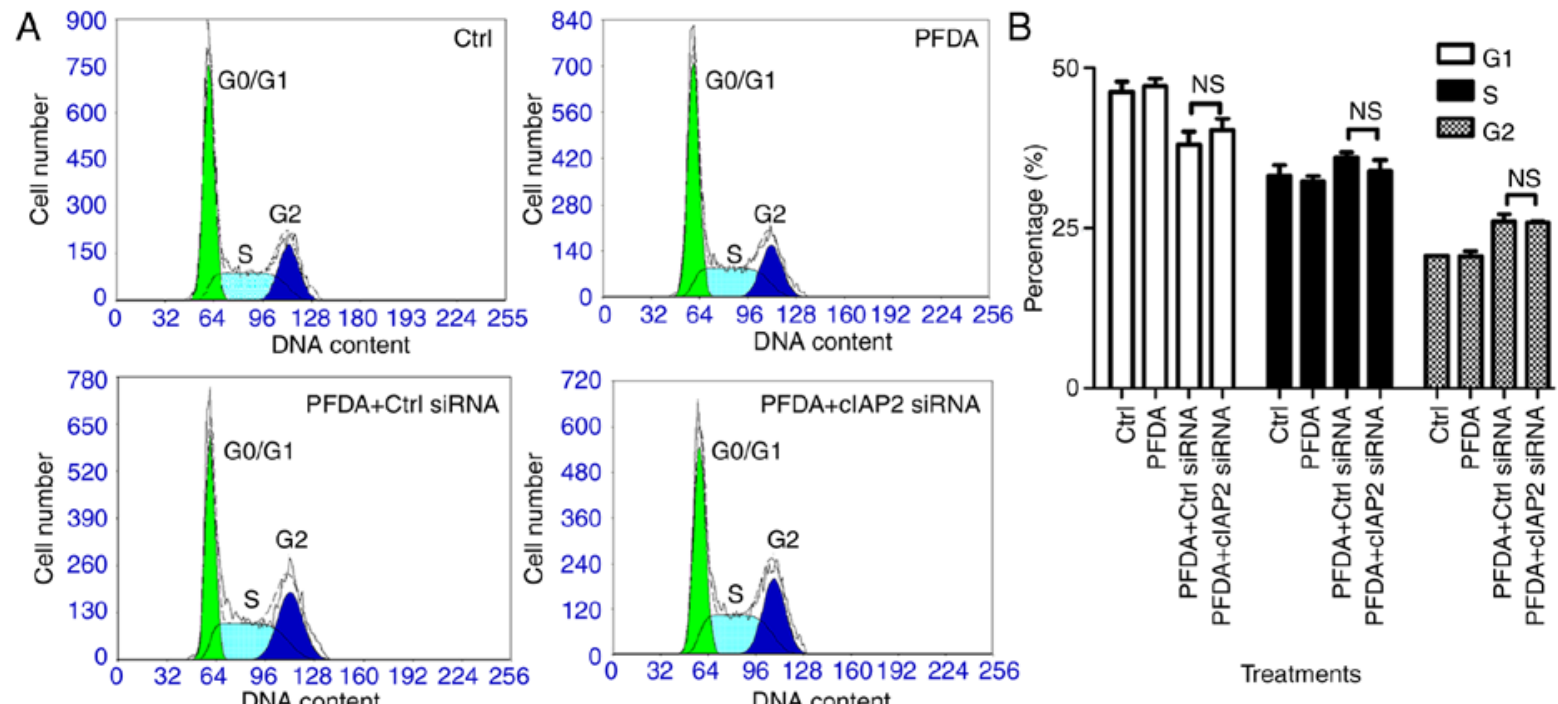

Figure 3. Knockdown of cIAP2 did not influence the cell cycle in AGS cells. (A) Histogram of the AGS cells cycle with PFDA and cIAP2 knockdown. (B) Quantification of cell cycle analysis results. Cell cycle analysis was performed as described in Materials and methods, 5x10 ${ }^{5}$ AGS cells/well was aliquot to 6-well plate for cell culture. PFDA, perfluorodecanoic acid.
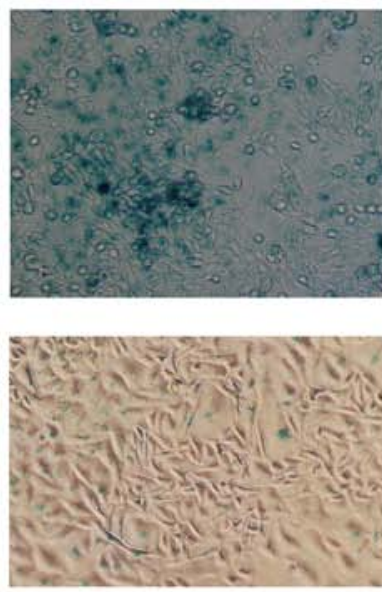

Ctrl
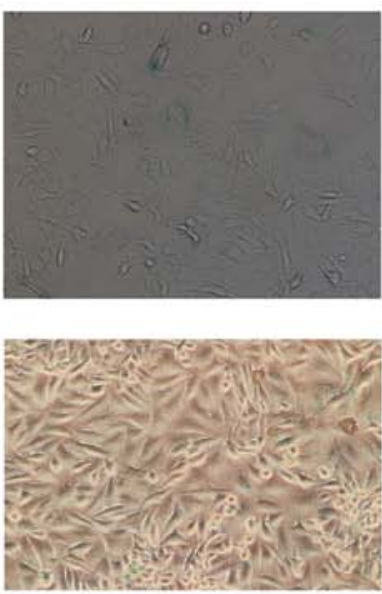

PFDA
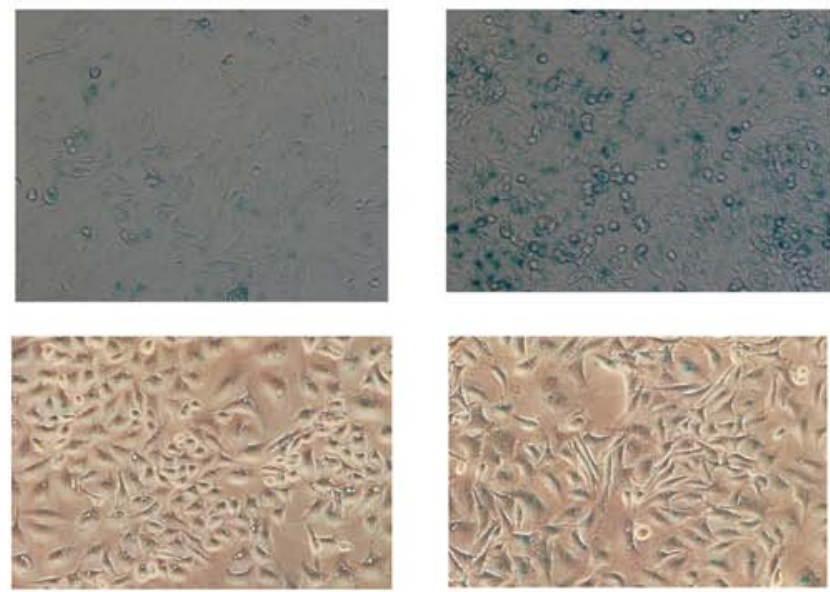

PFDA+Ctrl siRNA

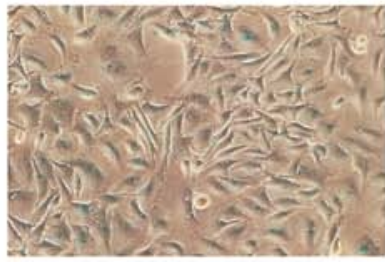

PFDA+CIAP2 siRNA

Figure 4. Effect of cIAP2 expression on cellular senescence of gastric cells with PFDA treatment. The top row: AGS cells; the bottom row, MGC-803 cells. Cellular senescence was determined by both the number of SA- $\beta$-gal-stained cells and staining intensity. Senescence-associated $\beta$-galactosidase (SA- $\beta$-gal) activity assessment was performed as described in Materials and methods; $1 \times 10^{4}$ AGS cells/well was aliquoted to a 24-well plate for cell culture. PFDA, perfluorodecanoic acid.

\section{Discussion}

Although the causes of cancer are complicated and now only partially understood, clinical studies have found that the expression of several specific bio-molecules were altered during the development of cancer. Such changes in expression may play key roles in many processes likely to be important for tumor progression, such as cell proliferation, cell motility, cell adhesion, cell survival and angiogenesis (37,38). Cellular inhibitor of apoptosis protein 2 (cIAP2), a member of the IAP protein family, was originally thought to have anti-apoptotic properties mediated by direct binding and inhibition of caspases-3, -7 and -9. However, it is now believed that the function of IAPs is mediated primarily by IAP-dependent ubiquitin (Ub) ligase activity $(39,40)$. This Ub ligase activity is responsible for most of the functions of cIAP2, including activation of NF- $\mathrm{KB}$ by both canonical and non-canonical pathways, which regulate the expression level of cIAP2 itself. IAP expression changes have been found in many types of human cancers, such as lung, liver and pancreatic cancer as well as glioblastoma $(41,42)$. In the present study, cIAP2 siRNA was employed to regulate cIAP2 expression following PFDA treatment. The results revealed that the growth rate of cIAP2-knockdown cells was reduced by approximately $50 \%$ compared to the control. In terms of mechanism, the research data indicated that cell senescence was significantly increased in the cIAP2-siRNA group in comparison to the control-siRNA group. Our research provided evidence that cIAP2 regulates cell senescence and thus regulates the number of gastric cells. 
A

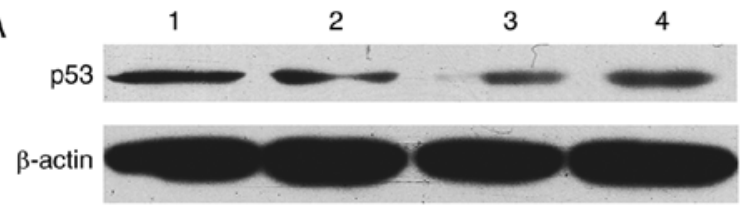

B

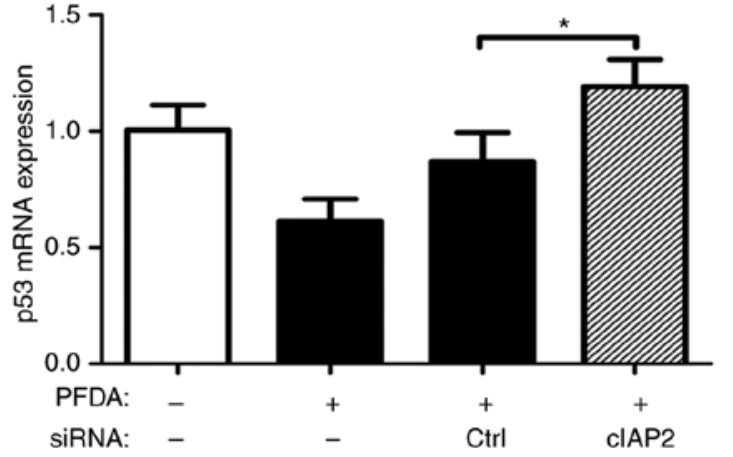

C

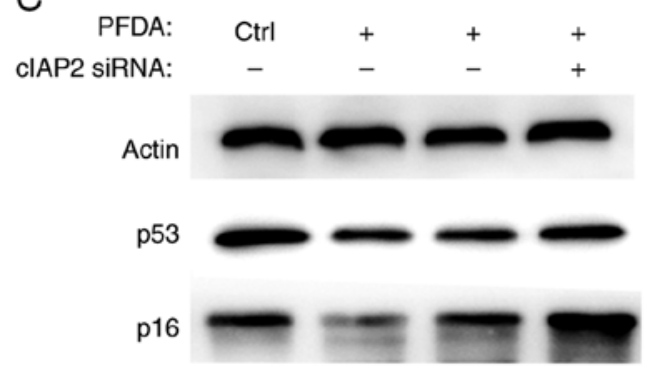

D
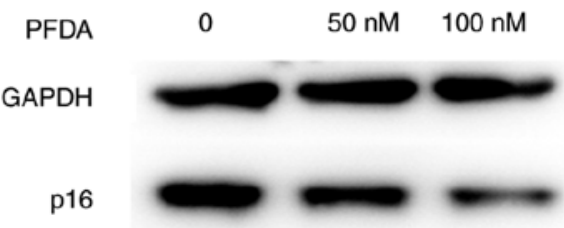

Figure 5. p53 is associated with cIAP2-cell induced proliferation promotion. (A) Western blot and (B) qRT-PCR analyses of protein and relative mRNA levels of p53 in the presence of PFDA treatment and cIAP2 interference. (C) Western blot analysis of p16 protein under the aforementioned conditions. (D) p16 expression was decreased in a dose-dependent manner in response to PFDA treatment in MGC-803 cells. Western blot analysis and RT-qPCR analyses were performed as described in Materials and methods. Cells used for Microarray and qPCR analysis were cells treated with PFDA for $60 \mathrm{~h}$; western blots harvested the proteins from the cells that were processed by PFDA for $72 \mathrm{~h}$. The PFDA concentration used to treat cells was $50 \mathrm{nM}$. "P<0.05. PFDA, perfluorodecanoic acid

The cell cycle is a series of well-organized molecular events that provide cells with the ability to produce their own copies accurately. DNA replication and chromosome segregation are the major events of the cell cycle. DNA replication takes place during the $\mathrm{S}$ phase, which is after the DNA synthesis preparation phase (G1 phase), whereas the mitosis preparation phase (G2 phase) occurs prior to mitosis (M phase). The $\mathrm{G} 1, \mathrm{~S}$, and $\mathrm{G} 2$ phases represent the interphase of cell proliferation, temporally the interval between two consecutive mitoses. Differentiated cells that do not proliferate enter the so-called G0 phase, which is a stable or quiescent phase (43). Although the expression of cIAP2 was reported to regulate cell cycle, the exact mechanism and functional consequence of this regulation are unknown (44). In the present study, we examined whether cIAP2 would lead to cell cycle variations and the research data revealed that the proportion of cells in the G1, S and G2 phases was not significantly altered with the decrease of cIAP2 expression. The reason for this phenomenon may be due to the specific pattern of the gene expression of the cell line itself we used. Conversely, it is also possible that PFDA inhibits the expression of a specific gene and thus inhibits the role of cIAP2 in mediating the cell cycle intermediate molecule.

Cell senescence is a decisive property of euploid cells in culture $(45,46)$. Several genes have been implicated as effectors of senescence, including important molecules in the growth regulatory pathway, such as p53 (47-50) and p16 (51-54). The need for p53 function during cell senescence reflects the accumulation of eroded chromosome ends resulting from inadequate telomerase activity in cells, leading to p53-dependent checkpoint arrest. Since p53 has been identified as a tumor suppressor and its molecular alterations are common in different human tumors, we investigated the relationship of p53 with cIAP2. The experimental results demonstrated that cIAP2 regulated the expression of p 53 and thus was likely to be a potential mechanism for PFDA-induced growth promotion. However, in the microarray data, there was no significant change in p53 expression, and its value was close to 1 . Since there are many modifications as well as regulatory mechanisms in the process of mRNA transcription to translation, the western blotting results which represent the actual protein expression levels, clearly revealed the difference in band densities (Fig. 5A and C). In addition, since the microarray data is generated by scanning the chip fluorescence signal from the top of the chip, the results of RT-qPCR could better reflect the small differences in gene expression in comparison to microarray analysis. Our RT-qPCR results revealed that the cells with PFDA treatment had 1.6 times mRNA level compared to control cells. Moreover, in our pevious research (33), we found that TCF4 and its downstream gene sPLA2-IIA regulated cell proliferation, but the affected downstream molecule was not clear. In the present study, we discovered the key role of cIAP2 in this process. cIAP2 not only played an important role in the secretion of interleukin as previously reported (55), but also downregulated the expression of p53. p53 is an important molecule that regulates cell apoptosis and the cell cycle, however apoptosis and the cell cycle did not exhibit the expected results after PFDA treatment and this may be related to downregulation of p53 and its downstream molecules.

Collectively, our experiments indicated that PFDA altered cell senescence through cIAP2, but its effect on apoptosis which was most relevant to cIAP2 was less pronounced. Since there are many types of processes that lead to cell death, and there are a myriad of signaling pathways and molecules related to these processes, there may be some unknown factors involved, and thus further studies are warranted to ascertain the present results.

\section{Acknowledgements}

Not applicable. 


\section{Funding}

We gratefully acknowledge the financial support from The Cheung Kong Scholars Program (2015) and The Fundamental Research Funds of Shandong University (2015JC010).

\section{Availability of data and materials}

The datasets used during the present study are available from the corresponding author upon reasonable request.

\section{Authors' contributions}

SL, ZZ, NS, YP, ZF, MZ and TD acquired the data and created a draft of the manuscript; SL, MH, ZZ, NS, YP, ZF, MZ and TD prepared the experimental materials and performed the in vitro assays; SL, ZZ and TD interpreted the data, performed the statistical analysis and analyzed the results; SL, NS and $\mathrm{ZZ}$ revised and approved the final version of the manuscript. All authors read and approved the manuscript and agree to be accountable for all aspects of the research in ensuring that the accuracy or integrity of any part of the work are appropriately investigated and resolved.

\section{Ethics approval and consent to participate}

Not applicable.

\section{Patient consent for publication}

Not applicable.

\section{Competing interests}

The authors declare that they have no competing interests.

\section{References}

1. Ashley DJ: Environmental factors in the aetiology of gastric cancer. Br J Prev Soc Med 23: 187-189, 1969.

2. Winkelstein WJ and Kantor S: Stomach cancer. Positive association with suspended particulate air pollution. Arch Environ Health 18: 544-547, 1969.

3. Zou X: Environmental pollution and epidemic of common cancers in China. Ke Ji Dao Bao 32: 58-64, 2014.

4. Guenthner R and Vietork L: Surface active materials from perfluorocarboxylic and perfluorosulfonilic acids. I\&ED Prod Res Dev 1: 165-169, 1962.

5. Shinoda K and Nomura T: Miscibility of fluorocarbon and hydrocarbon surfactant in micelles and liquid mixtures: Basic studies of oil repellent and fire extinguishing agents. J Phys Chem 8: 365-369, 1980

6. Mak YL, Taniyasu S, Yeung LW, Lu G, Jin L, Yang Y, Lam PK, Kannan K and Yamashita N: Perfluorinated compounds in tap water from China and several other countries. Environ Sci Technol 43: 4824-4829, 2009.

7. Wang JM, YY P, YL S and YQ C: Perfluorinated compounds pollution levels in snowfall of Beijing urban area. Scientia Sinica Chimica 41: 900-906, 2011.

8. Calafat AM, Kuklenyik Z, Reidy JA, Caudill SP, Tully JS and Needham LL: Serum concentrations of 11 polyfluoroalkyl compounds in the u.s. population: Data from the national health and nutrition examination survey (NHANES). Environ Sci Technol 41: 2237-2242, 2007.

9. Calafat AM, Wong LY, Kuklenyik Z, Reidy JA and Needham LL: Polyfluoroalkyl chemicals in the U.S. population: Data from the national health and nutrition examination survey (NHANES) 2003-2004 and comparisons with NHANES 1999-2000. Environ Health Perspect 115: 1596-1602, 2007.
10. Fei C, McLaughlin JK, Tarone RE and Olsen J: Fetal growth indicators and perfluorinated chemicals: A study in the Danish national birth cohort. Am J Epidemiol 168: 66-72, 2008.

11. Nguyen VT, Gin KY, Reinhard M and Liu C: Occurrence, fate, and fluxes of perfluorochemicals (PFCs) in an urban catchment: Marina reservoir, Singapore. Water Sci Technol 66: 2439-2446, 2012.

12. Olsen GW, Church TR, Larson EB, van Belle G, Lundberg JK, Hansen KJ, Burris JM, Mandel JH and Zobel LR: Serum concentrations of perfluorooctanesulfonate and other fluorochemicals in an elderly population from Seattle, Washington. Chemosphere 54: 1599-1611, 2004.

13. Tao L, Kannan K, Aldous KM, Mauer MP and Eadon GA: Biomonitoring of perfluorochemicals in plasma of New York State personnel responding to the World trade center disaster. Environ Sci Technol 42: 3472-3478, 2008.

14. Oono S, Matsubara E, Harada KH, Takagi S, Hamada S, Asakawa A, Inoue K, Watanabe I and Koizumi A: Survey of airborne polyfluorinated telomers in Keihan area, Japan. Bull Environ Contam Toxicol 80: 102-106, 2008.

15. Skutlarek D, Exner M and Färber H: Perfluorinated surfactants in surface and drinking waters. Environ Sci Pollut Res Int 13: 299-307, 2006.

16. George ME and Andersen ME: Toxic effects of nonadecafluoro-n-decanoic acid in rats. Toxicol Appl Pharmacol 85: 169-180, 1986.

17. Harris MW, Uraih LC and Birnbaum LS: Acute toxicity of perfluorodecanoic acid in C57BL/6 mice differs from 2,3,7,8-tetrachlorodibenzo-p-dioxin. Fundam Appl Toxicol 13: 723-736, 1989.

18. Chinje E, Kentish P, Jarnot B, George M and Gibson G: Induction of CYP4A subfamily by perfluorodecanoic acid: The rat and guinea pig as susceptible and non-susceptible species. Toxicol Lett 71: 69-75, 1994.

19. Kawashima Y, Kobayashi $\mathrm{H}$, Miura $\mathrm{H}$ and Kozuka $\mathrm{H}$ : Characterization of hepatic response of rat to administration of perfluorooctanoic acid and perfluorodecanoic acid at low levels. Toxicology 99: 169-178, 1995.

20. Reo NV, Narayanan L, Kling KB and Adinehzadeh M: Perfluorodecanoic acid, a peroxisome proliferator, activates phospholipase C, inhibits CTP: Phosphocholine cytidylyltransferase, and elevates diacylglycerol in rat liver. Toxicol Lett 86: 1-11, 1996.

21. Sterchele PF, Vanden Heuvel JP, Davis JW II, Shrago E, Knudsen J and Peterson RE: Induction of hepatic acyl-CoA-binding protein and liver fatty acid-binding protein by perfluorodecanoic acid in rats. Lack of correlation with hepatic long-chain acyl-CoA levels. Biochem Pharmacol 48: 955-966, 1994.

22. Vanden Heuvel JP: Perfluorodecanoic acid as a useful pharmacologic tool for the study of peroxisome proliferation. Gen Pharmac 27: 1123-1129, 1996.

23. Olson CT and Andersen ME: The acute toxicity of perfluorooctanoic and perfluorodecanoic acids in male rats and effects on tissue fatty acids. Toxicol Appl Pharmacol 70: 362-372, 1983.

24. Langley AE: Effects of perfluoro-n-decanoic acid on the respiratory activity of isolated rat liver mitochondria. J Toxicol Environ Health 29: 329-336, 1990.

25. Benninghoff AD, Bisson WH, Koch DC, Ehresman DJ, Kolluri SK and Williams DE: Estrogen-like activity of perfluoroalkyl acids in vivo and interaction with human and rainbow trout estrogen receptors in vitro. Toxicol Sci 120: 42-58, 2011.

26. Bookstaff RC, Moore RW, Ingall GB and Peterson RE: Androgenic deficiency in male rats treated with perfluorodecanoic acid. Toxicol Appl Pharmacol 104: 322-333, 1990.

27. Gutshall DM, Pilcher GD and Langley AE: Mechanism of the serum thyroid hormone lowering effect of perfluoro-n-decanoic acid (PFDA) in rats. J Toxicol Environ Health 28: 53-65, 1989.

28. Van Rafelghem MJ, Inhorn SL and Peterson RE: Effects of perfluorodecanoic acid on thyroid status in rats. Toxicol Appl Pharmacol 87: 430-439, 1987.

29. Borges T, Peterson RE, Pitot HC, Robertson LW and Glauert HP: Effect of the peroxisome proliferator perfluorodecanoic acid on the promotion of two-stage hepatocarcinogenesis in rats. Cancer Lett 72: 111-120, 1993.

30. Upham BL, Deocampo ND, Wurl B and Trosko JE: Inhibition of gap junctional intercellular communication by perfluorinated fatty acids is dependent on the chain length of the fluorinated tail. Int J Cancer 78: 491-495, 1998. 
31. Nelson DL,Frazier DE Jr,Ericson JE, Tarr MJ and Mathes LE: The effects of perfluorodecanoic acid (PFDA) on humoral, cellular, and innate immunity in Fischer 344 rats. Immunopharmacol Immunotoxicol 14: 925-938, 1992.

32. Klenow S, Heinemeyer G, Brambilla G, Dellatte E, Herzke D and de Voogt P: Dietary exposure to selected perfluoroalkyl acids (PFAAs) in four European regions. Food Addit Contam Part A Chem Anal Control Expo Risk Assess 30: 2141-2151, 2013.

33. Dong T, Peng Y, Zhong N, Liu F, Zhang H, Xu M, Liu R, Han M, Tian X, Jia J, et al: Perfluorodecanoic acid (PFDA) promotes gastric cell proliferation via sPLA2-IIA. Oncotarget 8: 50911-50920, 2017.

34. Deitch AD, Law H and deVere White R: A stable propidium iodide staining procedure for flow cytometry. J Histochem Cytochem 30: 967-972, 1982.

35. Cristofalo VJ: SA-beta-Gal staining: Biomarker or delusion. Exp Gerontol 40: 836-838, 2005.

36. Kurz DJ, Decary S, Hong Y and Erusalimsky JD: Senescenceassociated (beta)-galactosidase reflects an increase in lysosomal mass during replicative ageing of human endothelial cells. J Cell Sci 113: 3613-3622, 2000.

37. Hartwell LH and Kastan MB: Cell cycle control and cancer. Science 266: 1821-1828, 1994.

38. Woodburn JR: The epidermal growth factor receptor and its inhibition in cancer therapy. Pharmacol Ther 82: 241-250, 1999.

39. Gyrd-Hansen M and Meier P: IAPs: From caspase inhibitors to modulators of NF-kappaB, inflammation and cancer. Nat Rev Cancer 10: 561-574, 2010.

40. Pedersen J, LaCasse EC, Seidelin JB, Coskun M and Nielsen OH Inhibitors of apoptosis (IAPs) regulate intestinal immunity and inflammatory bowel disease (IBD) inflammation. Trends Mol Med 20: 652-665, 2014

41. Dai Z, Zhu WG, Morrison CD, Brena RM, Smiraglia DJ, Raval A, Wu YZ, Rush LJ, Ross P, Molina JR, et al: A comprehensive search for DNA amplification in lung cancer identifies inhibitors of apoptosis cIAP1 and cIAP2 as candidate oncogenes. Hum Mol Genet 12: 791-801, 2003.

42. Reardon DA, Michalkiewicz E, Boyett JM, Sublett JE, Entrekin RE, Ragsdale ST, Valentine MB, Behm FG, Li H, Heideman RL, et al: Extensive genomic abnormalities in childhood medulloblastoma by comparative genomic hybridization. Cancer Res 57: 4042-4047, 1997.

43. Vermeulen K, Van Bockstaele DR and Berneman ZN: The cell cycle: A review of regulation, deregulation and therapeutic targets in cancer. Cell Prolif 36: 131-149, 2003.
44. Jin HS and Lee TH: Cell cycle-dependent expression of cIAP2 at $\mathrm{G} 2 / \mathrm{M}$ phase contributes to survival during mitotic cell cycle arrest. Biochem J 399: 335-342, 2006.

45. Hayflick L and Moorhead PS: The serial cultivation of human diploid cell strains. Exp Cell Res 25: 585-621, 1961.

46. Hayflick L: The limited in vitro lifetime of human diploid cell strains. Exp Cell Res 37: 614-636, 1965.

47. Brown JP, Wei W and Sedivy JM: Bypass of senescence after disruption of $\mathrm{p} 21^{C I P I / W A F I}$ gene in normal diploid human fibroblasts. Science 277: 831-834, 1997

48. Xu HJ, Zhou Y, Ji W, Perng GS, Kruzelock R, Kong CT, Bast RC, Mills GB, Li J and Hu SX: Reexpression of the retinoblastoma protein in tumor cells induces senescence and telomerase inhibition. Oncogene 15: 2589-2596, 1997.

49. Rogan EM, Bryan TM, Hukku B, Maclean K, Chang AC, Moy EL, Englezou A, Warneford SG, Dalla-Pozza L and Reddel RR: Alterations in p53 and p16INK4 expression and telomere length during spontaneous immortalization of Li-Fraumeni syndrome fibroblasts. Mol Cell Biol 15: 4745-4753, 1995.

50. Whitaker NJ, Bryan TM, Bonnefin P, Chang AC, Musgrove EA, Braithwaite AW and Reddel RR: Involvement of RB-1, p53, p16INK4 and telomerase in immortalisation of human cells. Oncogene 11: 971-976, 1995.

51. Capparelli C, Chiavarina B, Whitaker-Menezes D, Pestell TG, Pestell RG, Hulit J, Andò S, Howell A, Martinez-Outschoorn UE, Sotgia F, et al: CDK inhibitors (p16/p19/p21) induce senescence and autophagy in cancer-associated fibroblasts, 'fueling' tumor growth via paracrine interactions, without an increase in neo-angiogenesis. Cell Cycle 11: 3599-3610, 2012.

52. Lin AW, Barradas M, Stone JC, van Aelst L, Serrano M and Lowe SW: Premature senescence involving p53 and p16 is activated in response to constitutive MEK/MAPK mitogenic signaling. Genes Dev 12: 3008-3019, 1998.

53. Helman A, Klochendler A, Azazmeh N, Gabai Y, Horwitz E, Anzi S, Swisa A, Condiotti R, Granit RZ, Nevo Y, et al: p16 ${ }^{\text {Ink4a }}$-induced senescence of pancreatic beta cells enhances insulin secretion. Nat Med 22: 412-420, 2016.

54. Marcoux S, Le ON, Langlois-Pelletier C, Laverdière C, Hatami A, Robaey $\mathrm{P}$ and Beauséjour CM: Expression of the senescence marker p16 ${ }^{\mathrm{INK} 4 \mathrm{a}}$ in skin biopsies of acute lymphoblastic leukemia survivors: A pilot study. Radiat Oncol 8: 252, 2013.

55. Zhou X, Dong T, Fan Z, Peng Y, Zhou R, Wang X, Song N, Han M, Fan B, Jia J and Liu S: Perfluorodecanoic acid stimulates NLRP3 inflammasome assembly in gastric cells. Sci Rep 7: 45468, 2017. 